\title{
Pseudoperspectivas / Realización de un Fotomontaje Diédrico
}

\author{
Pseudoperspectives / Making a Dihedral Photomontage
}

\author{
> Alejandro Folga \\ Facultad de Arquitectura, Uruguay. \\ alfotocopias@gmail.com
}

\begin{abstract}
As the term suggests, a pseudoperspective involves performing a false perspective, and is the result of combining two different projective systems: Diedric Orthogonal System with the Central perspective System. Despite its heterodox character, this nifty graphic resource is used since the invention of perspective. With the digital graphics development of pseudo-perspectives currently allows new expressive possibilities. In this paper an academic exercise conducted with students from a curriculum during the first year of a career in architecture is presented. This work consisted of performing a photomontage from an elevation or vertical section.
\end{abstract}

Keywords: Enseñanza; Arquitectura; Representación; Fotomontaje; Sistemas mixtos

\section{Introducción}

Una pseudoperspectiva surge como resultado de mixturar dos sistemas proyectivos diferentes: el Sistema Diédrico Ortogonal (SDO) y el Sistema Perspectivo Central (SPC). La forma más habitual de pseudoperspectiva consiste en una proyección en diédrico ortogonal (alzado o sección vertical) en la que algunos elementos se dibujan en perspectiva central.

En definitiva, una pseudoperspectiva es un recurso gráfico donde se combinan las ventajas conceptuales de mostrar las verdaderas dimensiones de un objeto, que se presentan en el SDO; con la representación figurativa de la profundidad espacial, característica del SPC; consiguiendo así una representación híbrida.

Por su carácter heterodoxo este tipo de representación aparece someramente explicada en la bibliografía sobre los sistemas de representación, donde se la menciona en forma casi siempre marginal y por lo general crítica.

La tendencia reprobatoria nace desde el propio término utilizado para definirlas; el prefijo pseudo presupone una "falsa" perspectiva, de forma que la connotación negativa funciona como una censura implícita.

A pesar de esto, diversos recursos gráficos que podemos relacionar con la pseudoperspectiva han gozado de un amplio arraigo en la representación de proyectos de arquitectura. Desde la invención de la Perspectiva Central hasta la contemporaneidad podemos encontrar numerosos ejemplos de utilización de este ingenioso recurso gráfico.

En su libro El sustrato racional de la representación del espacio, Pedro Cracco (2000) analiza un ejemplo de fachada que podemos incluir dentro del género de las pseudoperspectivas (Fig 1, izquierda). Él la describe como una vista en diédrico que luego fue "ambientada” con la visión cónica, obteniendo así una imagen más pictórica. Según Cracco se trata de una "licencia poética", admisible sólo en ciertos casos. (p.138).

Tradicionalmente, el tipo de representación que Cracco comenta era utilizada para incorporar el paisaje lejano en un alzado, pues, como los elementos más alejados se representan a menor escala permitía incluir objetos de gran tamaño (como edificios y montańas), característica difícil de obtener cuando el alzado se representa de manera "geométricamente correcta", como ocurre en el ejemplo de la Figura 1, derecha.

En la comparación de los dos ejemplos Cracco admite que el dibujo de la pseudoperspectiva es válido, pero lo define como un recurso "artístico", lo que funciona como una clara advertencia. Por tratarse de una representación heterodoxa, casi una anomalía, él la excluye del campo del conocimiento científico, por eso no merece ser estudiada, ni siquiera explicada en detalle. En definitiva, su manual se propone persuadirnos de que este tipo de ejemplos no se repitan, y para eso utiliza el clásico recurso didáctico de presentarnos un caso de lo que no debería hacerse.

En el ejemplo anterior lo que se expresa en perspectiva es el entorno lejano, aquello que está por detrás del plano de la fachada representada. No obstante, existe otro recurso consistente en perspectivar el plano horizontal que queda por delante de una fachada, de esta forma podemos sugerir el entorno más cercano, la espacialidad frontal de un edificio. 

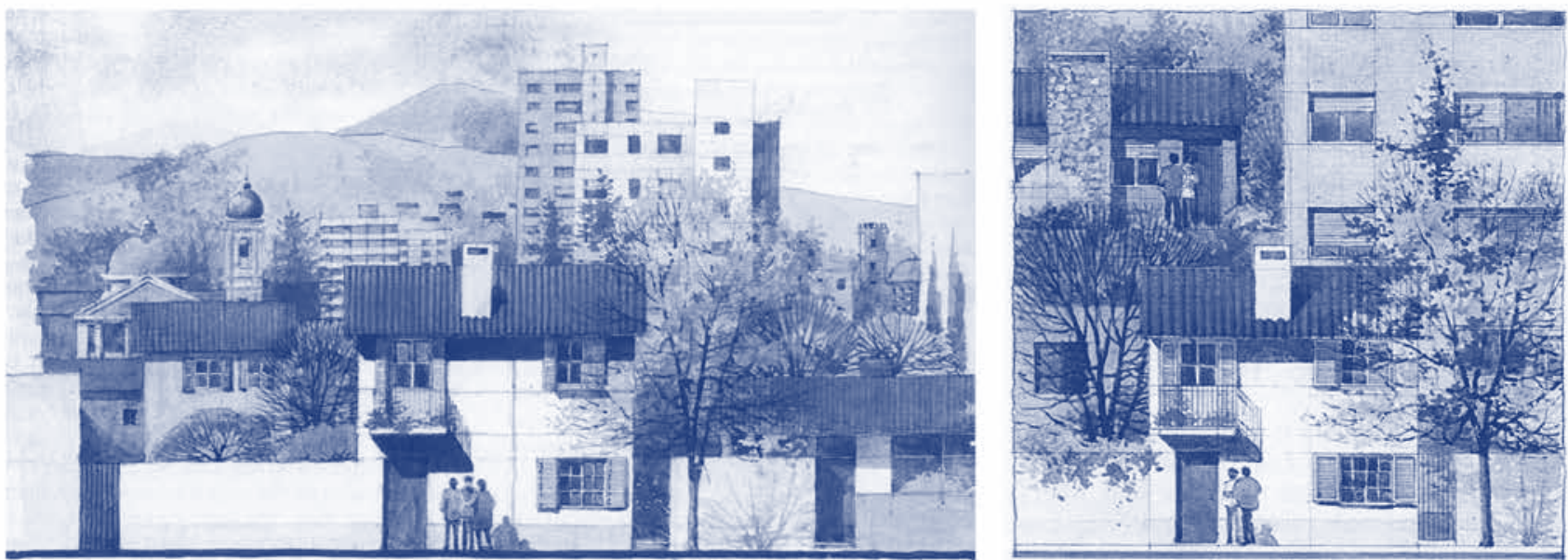

Figura 1: Una pseudoperspectiva (izquierda) y un alzado diédrico ortodoxo (derecha). Dibujos del Prof. Pedro Cracco (2000).

Sobre la función que cumple el plano base en este tipo de representaciones, Goodman y Porter (1985) defienden que la ambigüedad que presentan los alzados de alguna manera admite o "habilita" una lectura en perspectiva cónica: "Esta zona frontal suele interpretarse algunas veces gráficamente como plano horizontal más que como corte vertical. Su elaboración en tanto superficie intermedia entre el observador y la fachada marca el primer paso de la abstracción a la representación ilusoria del espacio." (p.50).
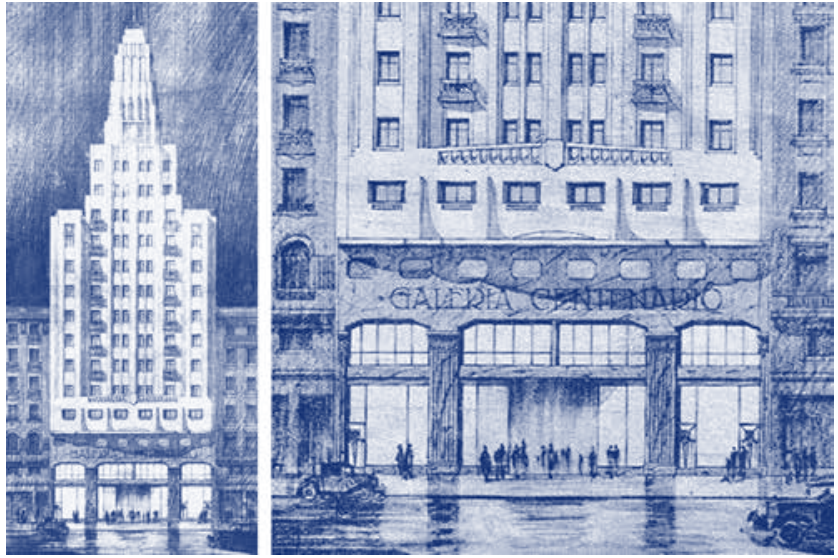

Figura 2: Palacio Díaz, (1929) ejemplo de una fachada diédrica con perspectiva y reflejos en el plano horizontal definido por la calle.

En el dibujo del Palacio Díaz (edificio art decó de 1929, ubicado en la ciudad de Montevideo, obra de de los arquitectos Gonzalo Vázquez Barriere y Rafael Ruano), el plano horizontal que está por delante del edificio se representa en perspectiva, de manera de focalizar la atención en el acceso y la calle (Fig. 2).

Perspectivar el plano de la calle permite incluir la expresión de los reflejos en el pavimento húmedo, a la vez que los elementos a mayor escala generan una sensación de profundidad que produce una imagen ambigua y sugerente.
Este dibujo plantea otra interesante "licencia poética": en el sector superior la volumetría se expresa mediante la iluminación del sol, mientras en el sector del acceso se muestra una situación nocturna.

Si bien la práctica de estos recursos tiene larga data, será la introducción de la fotografía, a principios del siglo XX, la que permitirá nuevas exploraciones. Particularmente, fueron las vanguardias modernas quienes hicieron uso de fotomontajes y collages donde se aplicaban recursos análogos a la pseudoperspectiva.

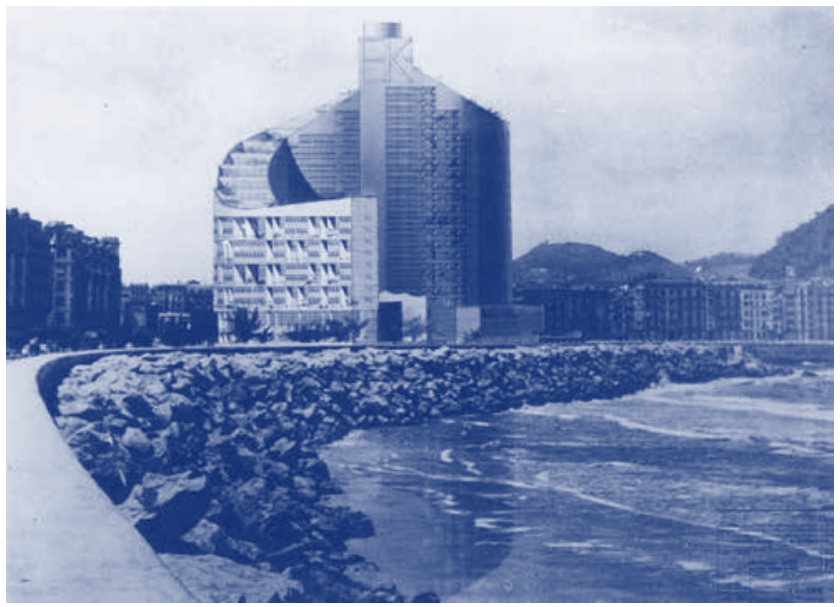

Figura 3: Fotomontaje diédrico. Arquitecto Mario Payssé Reyes, Concurso Euro Kursaal (San Sebastián, España, 1965).

El anteproyecto para el Concurso Euro Kursaal (1965) del arquitecto uruguayo Mario Payssé Reyes, presenta un interesante ejemplo que ilustra el uso del fotomontaje diédrico. En este caso se trata de un alzado de la propuesta que se inserta en una fotografía del sitio. (Fig. 3).

La integración consistente del alzado es posible gracias a que el punto de vista de la toma fotográfica está muy alejado del sitio concreto donde se implanta el nuevo edificio. El murallón curvo que bordea la rambla establece un corte prácticamente horizontal, lo que permite que el dibujo diédrico se inserte sin dificultad en la fotografía. 
En este caso la fotografía permite representar simultáneamente el entorno lejano y también el cercano, además de aprovechar la presencia del mar para sugerir el reflejo del nuevo edificio.

Por el predominio de la fotografía sobre los elementos dibujados el resultado se reconoce más como una perspectiva que como un alzado.

Gracias a los gráficos digitales la elaboración de pseudoperspectivas admite en la actualidad nuevas posibilidades expresivas. La fotografía digital, los programas de dibujo vectorial, de modelado tridimensional y de edición de imágenes habilitan a realizar complejas mixturas de sistemas y técnicas que renuevan el interés en el estudio y la aplicación de este recurso tradicional de expresión gráfica.

En esta ponencia se describe una experiencia académica realizada en 2012 y 2013 con estudiantes de un curso curricular (Anteproyecto Introductorio del Taller de Betolaza) perteneciente al primer año de la carrera de Arquitectura. Esta experiencia consistió en la realización de un fotomontaje diédrico a partir de herramientas gráficas digitales.

En la ponencia se exponen los principios geométricos y expresivos y las herramientas digitales ensayadas, se desarrolla la metodología didáctica empleada con los estudiantes, se analizan los criterios gráficos en diferentes casos estudiados y se comentan e ilustran algunos de los resultados obtenidos.

Algunos de los temas desarrollados de este trabajo ya fueron parcialmente tratados en la investigación inédita Imágenes e Ideas de la Arquitectura (2009), y luego expuestos en el libro Código Gráfico (2011) en un capítulo dedicado a Piezas Especiales. Asimismo, es posible consultar otra ponencia que recientemente hemos presentado sobre la temática del "Fotomontaje en Sección Perspectiva" (2014), Congreso EGraFía, realizado en Rosario, Argentina.

\section{Metodologia}

Para llevar a cabo la actividad se partió de gráficos en formato vectorial del anteproyecto que los estudiantes estaban realizando (un alzado o una sección vertical), y de fotografías digitales tomadas por los propios estudiantes en las visitas al sitio de proyecto.

En primer lugar, para poder compatibilizar los gráficos en diédrico con las fotografías, se instruyó a los estudiantes en algunas técnicas de procesamiento de imágenes mediante programas de edición de gráficos digitales.

Estas técnicas incluyen herramientas de ajuste de imágenes: mejora de valores, saturación del color, desenfoques, transparencias, filtros; y herramientas de transformación y corrección geométrica: unión y extensión de fotografías, composición de imágenes panorámicas, corrección de fugantes verticales, etc.

En segundo lugar, dado que se trataba de estudiantes que poseían muy escasa experiencia en la representación de un proyecto, el ejercicio partió de una clase teórica donde se realizaron análisis de una serie de paradigmas gráficos: imágenes de gran valor técnico y expresivo realizadas por estudios profesionales que han utilizado pseudoperspectivas para presentar sus ideas.

A partir del análisis de ejemplos se buscaba explicitar los principios geométricos y expresivos que sustentan este tipo de representaciones, de forma que la clase teórica servía de apoyo para las decisiones tomadas en la realización práctica del trabajo.

De esta manera se proponía a los estudiantes una serie de procedimientos replicables, que constituían una metodología general que debía adaptarse a cada caso particular. Esta metodología se concreta en una serie de casos tipo, que se analizaron como desafíos o problemas a resolver. En esta ponencia plantearemos las tres situaciones más significativas.

\section{1/ Fotomontaje en fachada y en sección}

Realizar una sección implica eliminar o sustraer una parte del objeto para poder ver espacios que en una fachada quedan ocultos. Por ello los elementos más cercanos (y por tanto los de mayor tamaño) serán los que coincidan con el plano de corte.

En consecuencia cuando el fotomontaje se realiza a partir de una sección vertical sólo se podrá perspectivar el entorno lejano: todo aquello que queda por detrás del objeto representado. La diferencia entre el fotomontajes en corte y la fachada se puede apreciar en el ejemplo de la Figura 4.

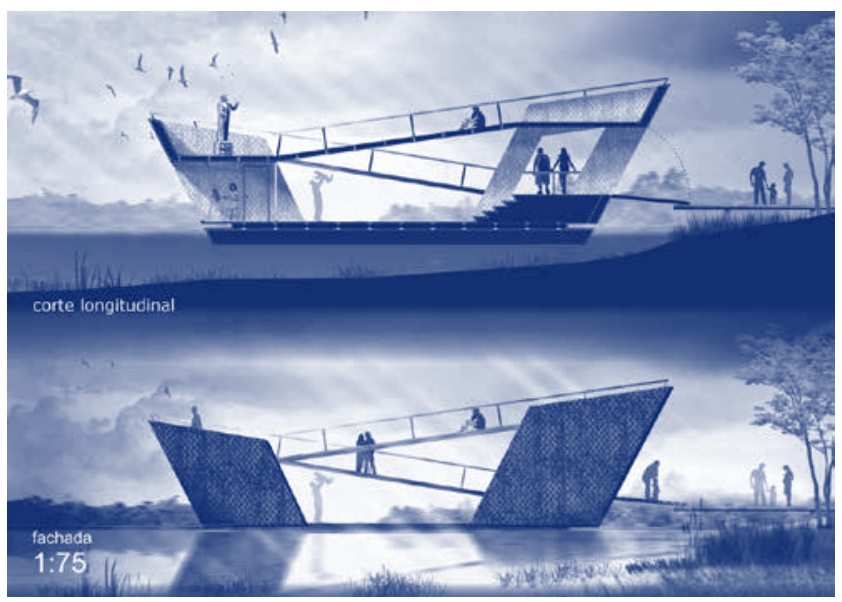

Figura 4: Fotomontajes de corte y fachada. Trabajo del estudiante Diego Cappelli (2012).

\section{2 / La superficie del agua y el horizonte}

Como un caso particular de fotomontaje en sección, un ejemplo analizado fueron entornos con presencia de grandes superficies de agua (lagunas, ríos, etc.). Cuando la sección se realiza por un sitio que debe seccionar el agua es conveniente que el plano horizontal definido por la superficie de agua no se vea afectado por la perspectiva.

La solución adoptada es que el plano se represente en diédrico, y esté definido mediante una línea que separa el agua seccionada del aire. Esto se ilustra en el ejemplo de la Figura 5, superior.

En cambio, en el caso en que el volumen de agua no esté seccionada, cuando queda por delante del plano de corte, resulta aceptable (aunque no ideal) que el plano horizontal se presente en perspectiva, de manera de poder mostrar la superficie de agua en la representación. En este caso es conveniente que la línea de horizonte de la fotografía coincida con la altura de la visión de un ser humano ubicado en el espacio más significativo de la propuesta (ver Figura 5, inferior). 


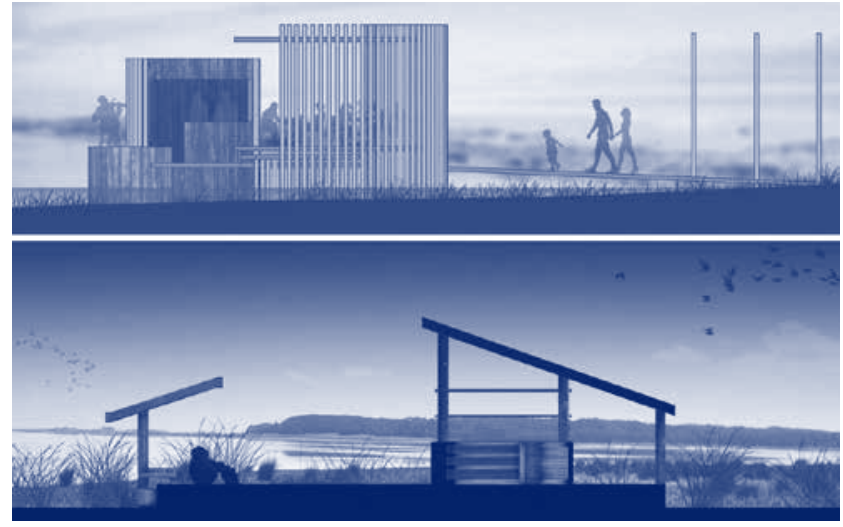

Figura 5: Trabajos de los estudiantes Sebastián Lambert y Estefany Fagián (2013)

\section{3/ Transgresiones expresivas}

Dado que las pseudoperspectivas no son técnicamente ortodoxas, permiten con mayor facilidad ciertos recursos expresivos alejados de la figuratividad fotográfica. Uno de estos recursos es la utilización selectiva del color.

En el primer ejemplo (Fig. 6, superior) el fondo se ve en escala de grises, lo que contribuye a diferenciarlo de la propuesta sugiriendo una distancia que lo separa del primer plano. Todos los elementos que se encuentran cercanos al plano de sección se representan en diédrico, con mayor contraste y aplicación selectiva de color.

En el segundo caso (Fig. 6, inferior) el color se aplica en forma monocromática, para ambientar el cielo y el agua, pero no así en los vegetales, que se presentan mediante grises.

\section{Resultados}

El ensayo realizado permitió concluir que la pseudoperspectiva es una herramienta efectiva para la realización de fotomontajes que expresen el ambiente o contexto donde se implanta una propuesta. Este tipo de recursos resulta especialmente adecuado en casos donde el contexto forma parte importante de la lectura de un proyecto.

En este sentido, cabe advertir que no todos las situaciones son iguales. La aplicación de estos recursos es más fácil cuando el contexto se puede presentar de forma genérica, como en el caso de paisajes naturales o espacios con predominancia de vegetación. En definitiva, lugares que no requieran precisión en la escala o en la orientación de los puntos de vista. En estos casos podremos tomarnos algunas licencias para aludir al carácter de un entorno.

En el caso de un entorno urbano serán más adecuadas las fotografías donde los objetos arquitectónicos sean frontales o estén muy alejados. Conviene que las tomas no presenten rectas fugantes marcadas, ni elementos muy perspectivados. En caso de que sea es posible será mejor ocultarlos o incluso recortar la fotografía para evitar que aparezcan en el fotomontaje.

Pero cuando el sitio posee atributos muy específicos (como edificios cercanos u objetos concretos que deben ser tomados como referencia y definidos claramente en sus relaciones geométricas y dimensionales) el trabajo de montaje debe ser cuidadoso, y puede llegar a ser incluso más complejo que un fotomontaje perspectivo.

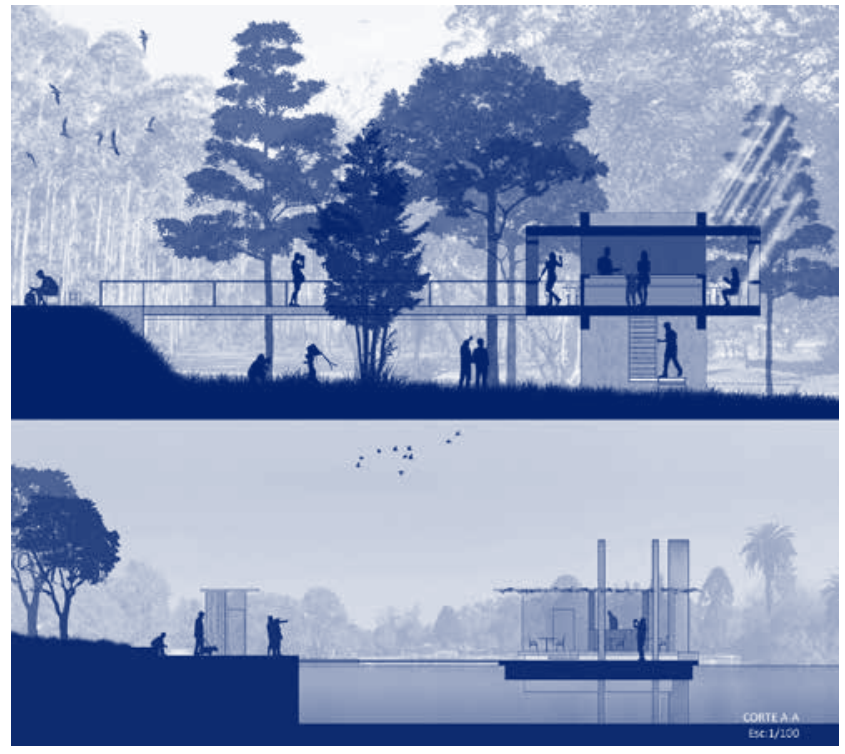

Figura 6: Trabajos de los estudiantes Rodrigo Figueredo y Cecilia de los Santos (2012)

\section{Debate}

La principal contribución disciplinar de este trabajo es el desafío de utilizar los nuevos medios para revalorizar un recurso tradicional de representación, que se muestra como una manera legítima y eficiente de representar arquitectura mediante herramientas informáticas.

El interés en este estudio surgió con motivo de la escasa difusión que existe sobre esta temática. Si bien este tipo de recursos son utilizados a nivel de la enseńanza universitaria y profesional, su práctica queda librada al criterio personal, a puro "ensayo y error".

Por ello la experiencia desarrollada pretendía generar una metodología, o al menos una serie de criterios para su correcta aplicación.

Podemos argumentar que históricamente la adopción de la pseudoperspectiva se justificaba por una mayor facilidad en la realización de un alzado con respecto a una perspectiva. Actualmente esta elección no siempre responde a una menor dificultad técnica, ya que cuando el alzado se obtiene a partir de un modelo $3 \mathrm{D}$ el procedimiento es prácticamente el mismo. En definitiva, una de las razones más claras para utilizar este tipo de recursos es simplemente que un alzado puede ser mejor que la perspectiva cónica para expresar algunas ideas proyectuales.

La representación gráfica arquitectónica está cada vez más vinculada a la utilización de los medios gráficos digitales. En este contexto consideramos que la enseńanza y el aprendizaje de las herramientas informáticas no deben propender a la mera repetición mecánica de soluciones ya establecidas y demostradas para conseguir siempre los mismos resultados.

El trabajo desarrollado nos permitió comprobar que el fotomontaje diédrico ofrece una vía de experimentación e innovación gráfica que redunda en una mayor libertad expresiva y proyectual, a la vez que permite adquirir y desarrollar nuevas habilidades en el manejo de las herramientas digitales. 
Por su complejidad este tipo de trabajos exige un mayor conocimiento y dominio de los sistemas proyectivos por parte de los estudiantes. Desde el punto de vista docente esta actividad se planteó como un desafío, ya que implicó aceptar ciertos riesgos en cuanto a los resultados finales que se obtendrían. No obstante consideramos que por esta vía se contribuye a generar en el estudiante un mayor compromiso personal con el trabajo, lo que a la larga implica la adquisición de una mayor autonomía en su propio proceso creativo.

Como reflexión final, este tipo de experiencias permite revalorizar la investigación realizada a partir de actividades de enseñanza. Esta vía constituye una manera de aprovechar la dedicación horaria y el enorme potencial creativo desplegado en los cursos curriculares. En definitiva, la enseñanza de grado constituye una cantera inagotable de trabajos de investigación que es necesario explotar más regularmente.

\section{Agradecimientos}

Debemos agradecer al equipo docente del curso de Anteproyecto Introductorio del Taller de Betolaza, integrado por los arquitectos: Juan Articardi (coordinador), Alejandro Folga, Daniela Garat y
Alberto De Matteo. También corresponde mencionar al Prof. Arq. Carlos Pantaleón, titular de la cátedra de Medios y Técnicas de Expresión, por su apoyo en la investigación que originó estas reflexiones. Finalmente a los estudiantes de Anteproyecto Introductorio, verdaderos motivadores y a la vez destinatarios de esta experiencia.

\section{Referencias}

Cracco, P. (2000). Sustrato Racional de la Representación del Espacio, Editorial Hemisferio Sur, Montevideo, 138-140.

Fernández, L., Folga, A., Garat, D., Pantaleón, C., Parodi, A. (2012): Código Gráfico. Montevideo, Facultad de Arquitectura, $203-207$.

Folga, A. (2009). Imágenes e Ideas en la Arquitectura, investigación inédita, Montevideo, Farq - UdelaR, 55-74.

Goodman, S. \& Porter, T. (1988) Manual de técnicas gráficas para arquitectos, diseñadores y artistas. Número 4, Barcelona, Editorial Gustavo Gili, 50 - 51.

Sainz, J. (2005). El dibujo de arquitectura: Teoría e historia de un lenguaje gráfico. Editorial Reverté, Barcelona, 130-132. 